\title{
THE IMPACT OF TQM PRACTICES ON KEY PERFORMANCE INDICATORS: EMPIRICAL EVIDENCE FROM AUTOMOTIVE DEALERSHIPS
}

\author{
Omar Sabbagh, Mohd Nizam Ab Rahman, Wan Rosmanira \\ Ismail, Wan Mohd Hirwani Wan Hussain
}

\section{Introduction}

The After-Sales (AS) service is becoming a strategic business driver to maintain longterm customer retention, customer satisfaction and capital revenue in such a manner that it guarantees the continuous improvement of products and services offered to customers; AS market is up to five times larger than the new product market (Bundschuh \& Dezvane, 2003), whilst it is widely agreed that the turnover of the original purchase can be tripled during the product lifespan by investing in AS services. Consequently, performance of the after-sales department should be well measured and monitored to achieve a balance between the business and the operational goals on the one hand, and their assessed values on the other (Cavalieri et al., 2007).

In this conception, Key Performance Indicators (KPIs) are quantifiable indicators that provide firm managers with financial and nonfinancial figures to assess the performance of their organisations and monitor their progress in achieving their pre-determined objectives. Therefore, KPIs play an outstanding role in tracking the firm's progress with which the decision makers may perform internal and external benchmarking (Sari, 2015).

Generally, the conventional performance management approaches measure the firm's financial indicators for determining the performance and financial status of the organisations. However, these measurements focus on the operational outcomes rather than taking into consideration internal processes, this entails long-term repercussions due to a lack of forecasting functions and orientation (Sofiyabadi et al., 2015). On the other hand, non-financial performance indicators are significantly ignored by managers in the non- manufacturing sector, who eventually perceive their importance but avoid using them and hence this may create a gap between the perception and implementation of non-financial indicators (Sawang, 2011).

The relationship between quality and performance management has been tested since the early 1980s, wherein the research outcomes show a positive influence of quality management on organisational performance. Likewise, scholars have switched to investigate the relationship between quality practises and performance; while their findings have indicated that this relationship is still controversial. In this respect, several scholars have empirically proven that there is a positive influence of TQM on firm performance, whereas other scholars have established its negative impact (Prajogo \& Sohal, 2003).

Although performance measurement is an attractive topic to investigate in the industrial and academic fields, the adaptation of the correct and appropriate performance measures continues to be elusive for many organisations as these measures are interlinked with the business context and biased to measure the financial aspect (Kurdve et al., 2014). Moreover, the research conducted on TQM and organisational performance in the after-sales business is not frequent as a majority of the studies examine the implementation of TQM practices in relation with the organisational performance in the manufacturing discipline (Leong et al., 2012). In addition, there is a sparse literature on the implementation of TQM in the context of service sector (Kumar et al., 2011). Therefore, this study aims to examine the implementation of TQM practices in the context of automotive service centres and to test the implications of these practices on the 
financial and non-financial KPIs. Therefore, the authors attempt to answer the following questions:

1. Are the TQM practices equivalently applicable across the service and manufacturing sectors?

2. Do the financial and non-financial aspects of KPIs sufficiently measure the organisation performance?

3. Do TQM practices influence after sales KPIs?

To answer these questions, this article examines a conceptual framework with the help of the partial least squares structural equation modelling (PLS SEM) analysis method. PLS SEM can concurrently examine the relationships among a wide range of variables as it provides a statistical validation for complex models with high order latent variables, as well as it permits the authors to test formative constructs in a rigorous and reliable manner. The following part of this paper presents the literature review of the conceptual model with its supportive research hypotheses followed by the methodological procedure employed in data collection and sample size determination. The next section then displays the results and draws the conclusion, to end with a discussion of the implications as well as the research limitations.

\section{Theoretical Background}

\subsection{KPIs and Multidimensional Performance Measurements}

The multi-facets of organisational performance measurement is emphasised in literature (Bentes et al., 2012). KPIs are considered a helpful benchmarking tool used in determining how well the firms are keeping up with their objectives and in detecting the gaps that exist in their performances (Smith, 2014). They provide the ability to detect the problems and respond accordingly in order to prevent problems magnification. Velimirović, Stanković and Rade (2011) have investigated the essence of KPIs and the criticality of measuring organisational performance by testing the measurement of KPIs in TOYOTA dealerships as a part of the organisational process that implies customer orientation. Furthermore, Biondi et al. (2013) developed a model that evaluates the performance of car dealerships in terms of market share and target efficiency of annual sales for each dealership.
As a result, the performance management topic rouses high interest for both scholars and practitioners. However, the qualitative analysis of organisational performance such as good, bad and moderate is no longer sufficiently valid due to the difficulty in expressing the value of the performance, and thus the quantitative (numeric) measures are more commonly adopted since the required data for such analysis are usually available. Nevertheless, these numeric measures fail to fully capture the system's performance as it is difficult to determine the scope of the performance indicators that describe the performance status (Cavalieri et al., 2007). Therefore, a holistic research is required to tackle the corporate financial and non-financial aspects of key performance indicators.

\subsection{TQM Practices and Performance}

There is abundant literature on the relationship between TQM practices and various layers of organisational performance. It has also been proven that a positive influence exists between implementation of TQM practices and organisational performance in both manufacturing and service firms (Claver-Cortés et al., 2008). However, empirical studies draw inconsistent conclusions in determining the extent to which quality practices are capable of affecting the organisation's performance. The failure to obtain consistent results is mainly attributed to research design issues, where some scholars measure TQM as one construct, while the others define TQM as a multidimensional construct (Kaynak, 2003). In addition, performance measurement varies among these studies as some of them consider the financial performance aspect, while others adopt the operational performance dimension (Nair, 2006). Finally, the employed tools of data analysis lack sufficient research in determining which of the TQM practices have a higher influence on organisational performance (Kaynak, 2003). Surprisingly, depicting the causal linkage between TQM and the firm's multidimensional performance is not frequently dealt with in literature.

TQM measurements are not standardised in literature. In other words, different dimensional variables are utilised to measure one TQM construct (Kaynak, 2003). Recent studies have channelled the effect of each dimension of TQM practices on the organisational performance 
separately. Fotopoulos and Psomas (2009) have investigated the TQM soft and hard dimensions, where the soft dimensions are integrated with managerial concepts, such as leadership and human resource management; while the hard dimensions refer to the quality optimisation tools and techniques. They concluded that soft TQM elements have major effects on customer satisfaction and financial performance. Generally, in service provider firms the combination of soft and hard methodologies can provide managers with quantitative figures that measure the outcome of the adopted and committed practices by the employees (Pessôa et al., 2015). In this respect, Rahman and Bullock (2005) have discovered a significant relationship between soft and hard TQM practices, which affects positively the company's performance.

Likewise, literature reported empirical models investigating the relation between TQM's separate dimensions and performance. Corredor and Goñi (2011) developed a systematic approach to determine the resulting performance of implementing TQM in firms that adopt TQM in different time intervals. The results confirm the positive impact on the firm's performance. Further, this study ascertains the necessity to consider other factors in measuring the performance. Besides, Calvo-Mora et al. (2014) consider the TQM technical factor as a mediator in testing the relationship between TQM social factors and the organisation's results. Last, Valmohammadi (2011) proposes a conceptual model by which he examines the distinctive relationships between TQM practices on organisational performance. However, the results fail to draw a consistent conclusion as TQM practices impose asymmetric influence on organisational performance. Hence, we hypothesize that:

H1: TQM practices in the automotive service centres are positively influencing the after-sales KPI.

\section{Methodology}

\subsection{Conceptual Framework}

The authors employ a quantitative methodology in which a structured questionnaire is administrated to collect the required data. This approach is characterized by addressing the context of the service centres in automotive authorised dealerships. This research examines a conceptual framework with the help of the partial least square structural equation modelling, PLS SEM methodology. PLS SEM permits the researchers to test formative constructs such as performance, and it guarantees a better holistic and robust statistical analysis for complex models with higher order constructs (Hair et al., 2014). The conceptual framework shown in Fig. 1 is extracted from the extant literature and will be empirically tested by the methodological procedures presented in the next section.

\subsection{Questionnaire Building}

The structured questionnaire is the data collection instrument used in this study. The questionnaire comprises four main sections, where the first two sections provide biographical information on the respondent and its related company; the third section comprises of 72 items representing the 9 dimensions of TQM practices; and the final section consists of 7 items structuring the reflective construct of $\mathrm{KPI}$. As explained in Tab. 1. A five-point Likert scale ranging from 1 to 5 , where $1=$ strongly disagree and $5=$ strongly agree, is employed to indicate the level of agreement by the respondent in implementing the TQM practices, whereas, the variety of KPI values capture firm performance. While the authors have selected 7 indicators rated in a scale of 1 to 5 , where $1=$ very bad and $5=$ very good. These KPIs are extracted from previous studies addressing the automotive (Velimirović, Stanković, \& Rade, 2011; Smith, 2014).

The authors have conducted a pilot study to detect any issues in relation to the wording of questions, sequence and statement contents. Twelve draft questionnaires were distributed between two different groups of experts: (i) senior managers who have a long-term experience in the automotive service business; and (ii) senior experts in the academic field with profound relations with the automotive aftersales paradigm). The comments reveal that the questionnaire requires minor amendments in rephrasing the questions in order to remove the complexity in the question statements and for use in the actual study, these comments has been undertaken in the final version of the questionnaire.

\subsection{Sample and Data Collection}

Malaysian automotive after-sales market is selected to conduct the survey that is targeted 


\section{Business Administration and Management}

Tab. 1: KPIs in automotive service centres

\begin{tabular}{l|l}
\multicolumn{1}{c|}{ KPI in service centre } & \\
\hline K.1 Labour Utilization & $=$ Hours work / Hour attended \\
\hline K.2 Overall Productivity & $=$ Hours sold / Hours worked \\
\hline K.3 Overall Efficiency & $=$ Hours sold / Hours attended \\
\hline K.4 Labour gross profit ratio & $=$ Labour gross profit / Labour sales \\
\hline K.5 Oil \& Lubricants profitability ratio & $=$ Oil gross profit / Oil sales \\
\hline K.6 Parts gross profit ratio & $=$ Gross profit / Service centre turnover \\
\hline K.7 Over all service centre Profit ratio & $=$ Service centre profit / Turnover \\
\hline
\end{tabular}

Source: Smith (2014)

\section{Fig. 1: Conceptual model}

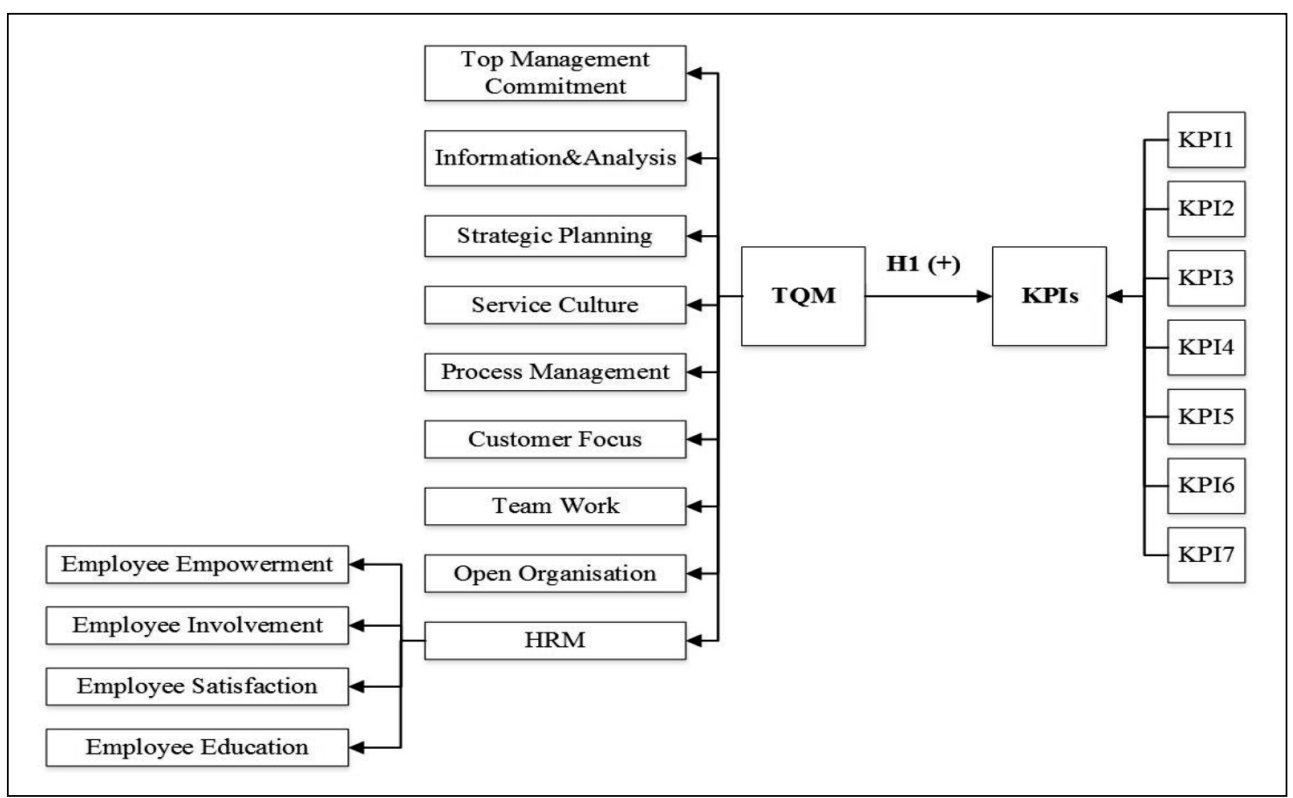

Source: Valmohammadi (2011)

at the service managers in automotive service centres. In line with this, the managerial positions of automotive service centres represent the target population of this research as the service managers are well qualified to report on quality practices and performance indicators of their companies in behalf of their subordinates (Ooi, 2014).

Firstly, telephone information and email addresses for 561 authorised service centres in Malaysia were collected at the Malaysia Automotive Institute (MAI). Emails were sent to the service managers attached with an official letter outlining the academic research objectives in the manner that motivates the respondents to participate in this research. Besides, this research is conducted on selected firms located in Malaysia, namely Kuala Lumpur, Selangor, Penang, Perak and Melaka due to the reason that these Malaysian states 
are the most industrialised states, in which most leading manufacturing and service companies are situated (Ooi, 2014).

A total number of 120 complete questionnaires were provided; out of which the researchers have excluded 4 due to incomplete data and the remaining 116 valid questionnaires represents a total response rate of $20.68 \%$. This response rate is considered to be adequate compared with other response rates, which range between $8 \%$ and $28 \%$ in the studies discussing the TQM paradigm (Hung et al., 2011; Jabbour et al., 2013; Large \& Thomsen, 2011). Among the respondents, $55 \%$ came from small sized service firms (530 employees), $35 \%$ from medium sized firms (30-75 employees), $8 \%$ from large firms (over 75 employees), and $2 \%$ from micro sized firms (below 5 employees). The segregation of the size of firms is determined in respect to the number of employees according to SME Corporation Malaysia (SME, 2014).

\subsection{Data Analysis}

The conceptual models in Fig. 1 examines whether the TQM practices have an impact on KPIs by applying a variance-based structural equation modelling (SEM). SEM technique is employed to discover causal relationships among predefined variables and to provide rigorous validations for the findings. Technically, SEM permits to test concurrently the relationships for several sets of dependent variable, it represents the most reliable and efficient technique to simultaneously estimate series of multiple regression equations and the ability to test unobserved (latent) variables embodied in causal relationships (Hair et al., 2009). The authors employ the partial least square technique, or PLS due to the following reasons: 1) the advantage of dealing with complex models with high order constructs; 2) PLS handles formative-reflective constructs efficiently (Calvo-Mora et al., 2015). The Smart PLS V3 program is used to test the hypothesised relationships among the constructs.

\section{Results}

Two stages of PLS analysis must be applied: 1) the measurement model assessment; and 2) the structural model assessment (Suarez et al., 2016).

\subsection{Measurement Model Assessment}

As in the conceptual model, which combines two types of latent constructs: formative and reflective, the structural model assessment analysis also considers both types of constructs.

\section{Reflective Construct Structural Assessment}

The TQM construct is considered the third order reflective latent variable, which is complied with prior studies tackling TQM paradigm; such as (Lam, Lee, Ooi, \& Phusavat, 2013). Becker et al. (2012) proclaim that operationalising highorder constructs is receiving more attention from scholars in recent years, where validity and reliability criterions are achievable in SEM PLS technique.

Reliability test determines to what extent the construct is free of errors and able to generate consistent results (Arokiasamy \& Tat, 2014). Based on the fact that the TQM construct is the third order reflective latent variable, the measurement model assessment hence depends on the validity and reliability tests (Calvo-Mora et al., 2014). The composite reliability (CR) and Cronbach's alpha signify the reliability in the reflective latent variable; it represents the required internal consistency among the latent variables, while the threshold value is $>0.7$. In addition, the indicator loadings should exceed the 0.7 threshold; whereas AVE (Average Variance Extracted) indicates the convergent validity constraint, in which manner the variables should surpass the value of 0.5 . And lastly, the discriminant validity among variables in reflective high order constructs is not requested (Hair et al., 2014). It follows that the results demonstrate high reliability in the latent variables, as shown in Tab. 2 .

\section{Formative Construct}

The authors characterise the performance construct as a formative latent variable as it forms a composite of indicators instead of being a cause of them; it means that the indicators of one construct are interchangeable in the reflective construct, whereas they are not in the formative one. In this regard, the organisational performance construct can be measured by using a formative construct (Hair et al., 2014). Thus, the following steps are followed to test the formative construct: 1) Convergent validity: this tests the correlation with an alternative model by using single item reflective construct, where the threshold value should be higher than 0.8 . 


\section{Business Administration and Management}

\section{Tab. 2:}

\section{Reliability and AVE tests}

\begin{tabular}{l|c|c|c|c} 
Construct / Dimension / Indicator & Cronbach's alpha & CR & Loading & AVE \\
\hline TQM & 0.982 & 0.983 & - & 0.504 \\
\hline Strategic Planning (SP) & 0.950 & 0.957 & 0.946 & 0.671 \\
\hline Human resource (HR) & 0.947 & 0.954 & 0.925 & 0.557 \\
\hline Employee involvement (HR1) & 0.753 & 0.859 & 0.871 & 0.670 \\
\hline Employee satisfaction (HR2) & 0.894 & 0.922 & 0.920 & 0.702 \\
\hline Employee empowerment (HR3) & 0.715 & 0.875 & 0.809 & 0.778 \\
\hline Employee education (HR4) & 0.913 & 0.932 & 0.902 & 0.698 \\
\hline Information \& Analysis system (IA) & 0.933 & 0.946 & 0.909 & 0.717 \\
\hline Service culture (SC) & 0.905 & 0.941 & 0.754 & 0.841 \\
\hline Process management (PM) & 0.905 & 0.926 & 0.946 & 0.643 \\
\hline Top Mgt. Commitment (TMC) & 0.875 & 0.908 & 0.629 & 0.766 \\
\hline Open organisation (OO) & 0.848 & 0.895 & 0.841 & 0.681 \\
\hline Customer focus (CF) & 0.805 & 0.855 & 0.754 & 0.631 \\
\hline Team work (TW) & 0.774 & 0.898 & 0.728 & 0.815 \\
\hline
\end{tabular}

\section{Fig. 2: KPI formative construct redundancy test}

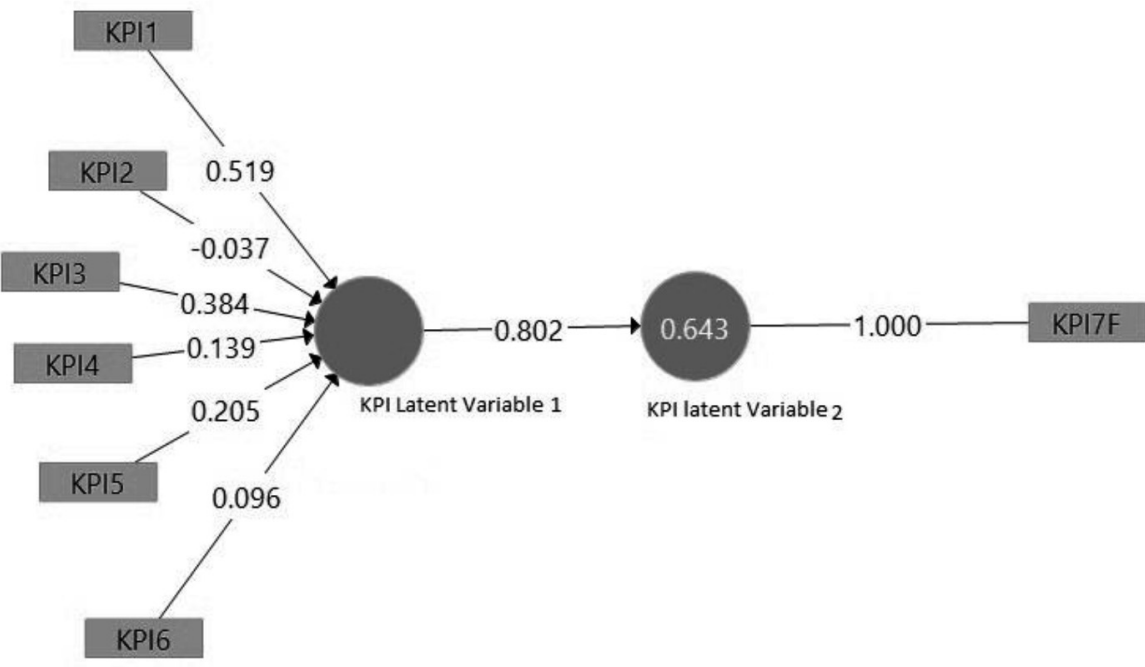




\begin{tabular}{l|c}
\multicolumn{1}{c|}{ Formative Construct Collinearity } & VIF \\
\hline KPI1 (Labour utilisation) & 2.336 \\
\hline KPI2 (Overall productivity) & 2.231 \\
\hline KPI3 (Overall efficiency) & 2.471 \\
\hline KPI4 (Labour gross profit) & 1.686 \\
\hline KPI5 (Oil \& Lubricant profitability) & 1.799 \\
\hline KPI6 (Parts profit) & 1.664 \\
\hline KPI7 (Departmental profit) & 2.798 \\
\hline
\end{tabular}

Fig. 2 indicates that convergent validity has been fulfilled wherein the latent variables 1, 2 represent the KPI formative construct.

2) Collinearity of indicators VIF: The assessment technique depends on calculating the tolerance, which is the value of variance of one formative indicator not explained by other indicator in the same construct, whilst the determinant value of collinearity is variance inflation factor VIF. The acceptable value of VIF is in the range of (0.2 to 5) (Hair et al., 2014). Tab. 3 proves that all indicators are in the accepted range.

3) Utilise bootstrapping function $(5,000$ samples) to test the outer weight and outer loading for each indicator, to determine whether delete or keep the indicator. Results indicate that KPI1, KPI4 and KPI7 are not significantly related to the main formative construct (T-test < 1.65). Nevertheless, as their outer loading is above 0.5 , the authors have decided to retain them (Hair et al., 2014). The T-test, loading and weight values are depicted in Tab. 4 accordingly.

\subsection{Structural Model}

It evaluates the proposed hypothesis between the exogenous and the endogenous constructs, the coefficient value ranges from $(-1$ to +1$)$ by which the relationship is determined positive or negative, where the closer to 0 the weaker the relationship and consequently non-significant (Mora et al., 2015). Fig. 3 below illustrates the results of the structural model.

1. Significant path coefficients assessment: in this test we use bootstrapping function in the smart PLS software with 5,000 subsamples to test the t-statistic value for each construct load $(\mathrm{t}=1.65$ where significance level $=10 \%$, $\mathrm{t}=1.96$ where significance level $=5 \%$, $t=2.57$ where significance level $=1 \%$ ). Tab. 5 shows that all path coefficients are significant, while Fig. 4 depicts the t-statistic values on the structural model.

\section{Tab. 4: T-test results KPI formative construct}

\begin{tabular}{l|c|c|c}
\multicolumn{1}{c|}{ Item } & Outer loading & Outer weight & T-test > 1.65 \\
\hline KPI1 & 0.615 & -0.119 & $\underline{0.637}$ \\
\hline KPI2 & 0.855 & 0.414 & 2.934 \\
\hline KPI3 & 0.871 & 0.563 & 4.051 \\
\hline KPI4 & 0.580 & 0.040 & $\underline{0.296}$ \\
\hline KPI5 & 0.318 & -0.281 & 2.018 \\
\hline KPI6 & 0.462 & 0.340 & 2.732 \\
\hline KPI7 & 0.720 & 0.192 & $\underline{1.133}$ \\
\hline
\end{tabular}




\section{Business Administration and Management}

\section{Tab. 5: Structural model path coefficient t-statistic values}

\begin{tabular}{l|l|l}
\multicolumn{1}{c|}{ Relationship } & Load & T-test \\
\hline HR $>$ HR1 & 0.902 & 35.375 \\
\hline HR $>$ HR2 & 0.871 & 33.731 \\
\hline HR $>$ HR3 & 0.920 & 71.083 \\
\hline HR $>$ HR4 & 0.809 & 15.162 \\
\hline TQM $>$ CF & 0.795 & 15.079 \\
\hline TQM > HR & 0.925 & 67.747 \\
\hline TQM > IA & 0.909 & 45.124 \\
\hline TQM > KPI & 0.731 & 16.812 \\
\hline TQM > OO & 0.841 & 28.140 \\
\hline TQM > PM & 0.898 & 35.294 \\
\hline TQM > SC & 0.754 & 14.889 \\
\hline TQM $>$ SP & 0.946 & 79.195 \\
\hline TQM $>$ TM & 0.728 & 15.023 \\
\hline TQM $>$ TMC & 0.635 & 11.270 \\
\hline
\end{tabular}

2. Coefficient of determination $R^{2}$ : This indicates the amount of variance in the endogenous construct explained by the entire exogenous construct, where generally the $R^{2}$ values of $0.25,0.5$ and 0.75 for the endogenous construct indicate weak, moderate and substantial relation. Hence, in our case, $\mathrm{R}^{2}=0.73$ represent a substantial relationship between TQM and KPI. Tab. 6 below illustrates the $\mathrm{R}^{2}$ results accordingly.

\section{Discussion}

This study proposes a multidimensional structural model to investigate the influence of TQM implementation on after-sales KPIs. The model captures the financial and non-financial dimensions of the KPIs as a formative latent variable, whereas TQM is represented by a third order reflective construct representing nine practices implemented in the service and manufacturing sectors. The obtained results reinforce the hypothesis that underlies the implementation of TQM practices and its positive effect on after-sales KPIs.

\section{Structural model $\mathbf{R}^{2}$ results}

\begin{tabular}{c|c|c|c} 
Construct & $\mathbf{R}^{\mathbf{2}}$ & Construct & $\mathbf{R}^{\mathbf{2}}$ \\
\hline CF & 0.632 & KPI & 0.534 \\
\hline HR & 0.856 & OO & 0.708 \\
\hline HR1 & 0.814 & PM & 0.807 \\
\hline HR2 & 0.759 & SP & 0.895 \\
\hline HR3 & 0.846 & TM & 0.529 \\
\hline HR4 & 0.654 & TMC & 0.396 \\
\hline IA & 0.827 & & \\
\hline
\end{tabular}




\section{Fig. 3: Structural model empirical results}

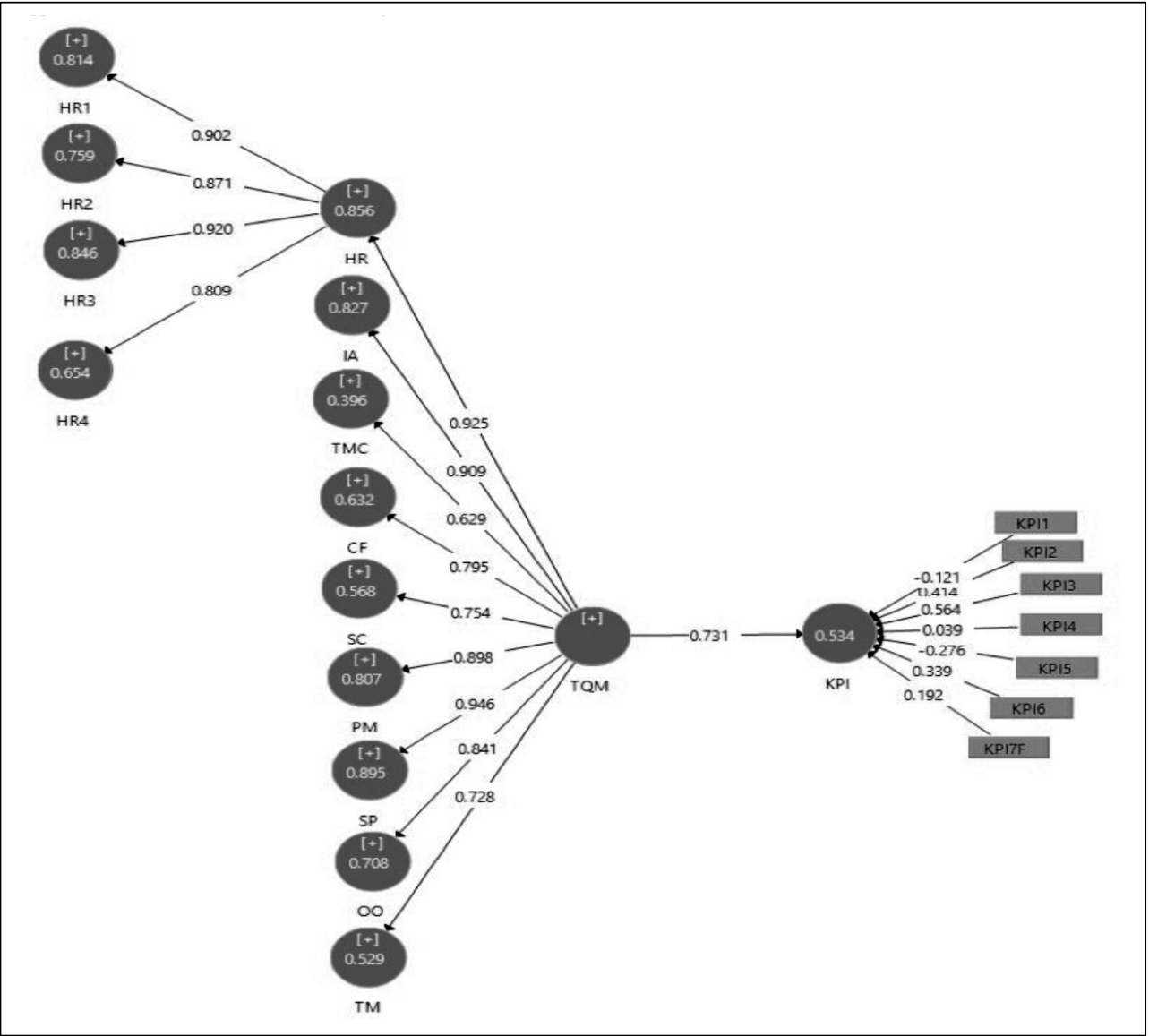

Source: own processing

The statistical test starts with the measurement model assessment in which the convergent and discriminant validity for the TQM third-order construct were carried out, followed by the assessment of the formative construct of $\mathrm{KPI}$ by which the seven KPI measures went through collinearity, redundancy and t-statistical tests and consequently proved sufficient validity. Lastly, the structural model assessment provides a valuable insight into confirming the significance relationship between TQM and KPIs in which the hypothesis $\mathrm{H} 1$ is supported, whilst the KPI explained variance was in moderate level.
The results provide an empirical evidence to the proposed model that is valid and reliable with considerable predictive power $\left(R^{2}=0.534\right)$ and predictive relevance $\left(q^{2}=0.203\right)$. More specifically, a superior quality of the indicators is fulfilled for both the TQM and the KPI latent variables. Firstly, the TQM indicators achieve sufficient average variance convergent extracted (AVE > 0.5, Cronbach's alpha > 0.7 and composite reliability $>0.7$ ), whereas, the KPI formative construct could pass the redundancy test $(>0.80)$ and collinearity criteria VIF in which all indicators are located in the range of 0.2 to 5 . However, although the t-test shows an insignificant relationship between the indicators 


\section{Business Administration and Management}

$\mathrm{KPI} 1, \mathrm{KPI} 4$ and $\mathrm{KPI} 7$ and the latent variable KPI; eliminating any one of them is not empirically useful due to reasonable achieved loading values (> 0.5) (Hair et al., 2014). Therefore, the KPI formative indicators achieve adequate quality in terms of reliability, redundancy and collinearity to be retained in the structural model assessment.

In detail, the results generated by PLS methodology validate the relationships among the variables in terms of 1) path coefficient: all values achieve a significant level of t-statistics (> 1.65) by utilising the bootstrapping function; 2 ) coefficient of determination $R^{2}$ by which the variance of endogenous variables are illustrated, with the results showing a considerable power in the relations among the variables ranging from 0.396 to $0.895 ; 3) f^{2}$ test examines the influence of the omitted exogenous variable on the endogenous one, with all retrieved results indicating a high importance of all exogenous variables; and 4) $q^{2}$ predictive relevance results are retrieved by employing the blindfolding test in which it confirms a medium predictive relevance power as the values range from 0.203 to 0.595 . Additionally, the heterogeneity and collinearity criteria are not required in the high order construct variables (Hair et al., 2014).

The proposed model exhibits overall significant relationships between the latent variables representing the TQM practice and the third order latent variable TQM. These empirical results provide evidence to the equivalent applicability of TQM practices across manufacturing and service sectors because the presented TQM practices are collected from previous research conducted in the both sectors. This conclusion is in line with previous studies (Ooi, 2014). On the other hand, the approaches in which the TQM practices are split into soft and hard practices, they contend that the soft TQM practices are the only applicable practices in service sector, and the

\section{Fig. 4: Structural model bootstrapping t-statistic results}

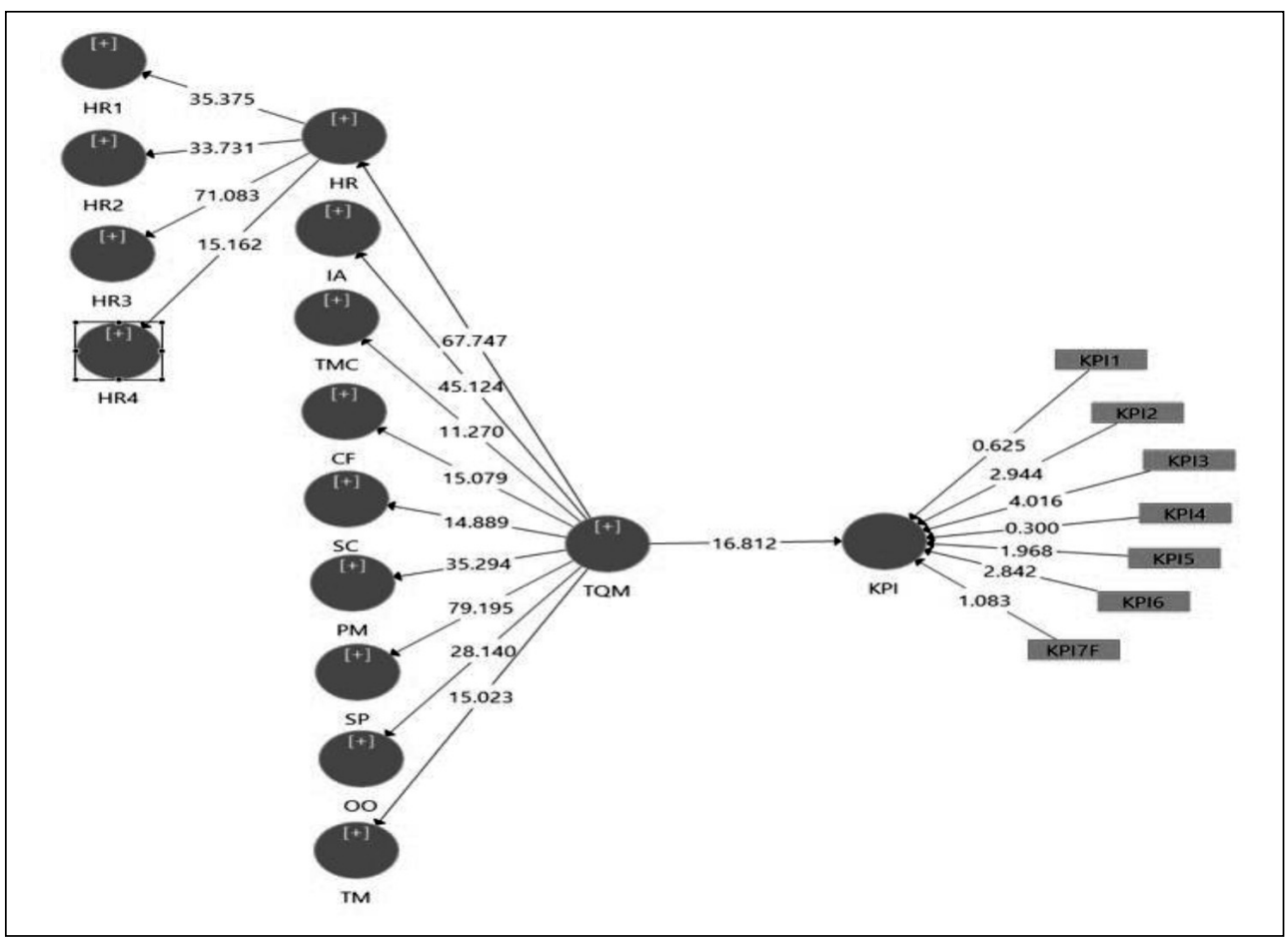


manufacturing sector operationalizes the soft and hard TQM practices (Chung Woon, 2000).

Interestingly, Sari (2015) emphasizes that individual essence of KPls as the performance indicators are adhered to the company's objectives and activities, while the balancing between these indicators represents a challenge; on this basis, the KPls opted in this research are extracted from prior studies tackling the automotive after sales discipline (Smith, 2014; Velimirović et al., 2011). Specifically, the statistical analysis of the KPIs formative construct emphasizes its multifacet structure that incorporates the financial and non-financial measures, which has been confirmed in literature (Barney, 2010; Bentes et al., 2012). On the other hand, this conclusion contradicts with the findings of Sawang (2011) in which he argued that the non-financial KPIs are not well recognized by managers, which required to introduce a moderator to depict these performance indicators in the after-sales discipline.

This research responds to the call to investigate the multi-oriented performance measures under the influence of TQM practices (Corredor \& Goñi, 2011). The empirical findings confirm the significant influence of TQM on $\mathrm{KPIs}$, which is in line with previous studies tackling the paradigms of TQM and performance management (Claver-Cortés et al., 2008). Apparently, operationalizing the TQM as one single construct serves the objective of this research to determine the overall influence of TQM on KPIs. Besides, the synergetic forming of non-financial and financial KPIs facilitates the drawing of a full picture of the organizational performance.

In comparison with previous studies tackling the relationship between TQM and performance employing multi-dimensional TQM construct to investigate distinctively the impact of each practice of TQM set on performance (Jayaram et al., 2010); these approaches generate inconsistent results in determining the degree of strength of this interlinkage between TQM and performance management, rather than the disability to draw a general conclusion delineating this relationship due to the reason that TQM practices induce different effects on performance (Kaynak, 2003).

In summary, the positive influence of TQM on multi-oriented performance measures KPIs is statistically proven and validated by developing a conceptual model, which reflects the research objective of generalizing and simplifying the relationship between TQM and $\mathrm{KPIs}$ in which the model design comprises a third-order reflective construct of TQM and first-order formative KPIs. Bear in mind the pitfalls of previous approaches in which the TQM construct is misrepresented: either by investigating either the soft or hard practices of TQM with performance, or by scrutinizing the distinctive TQM practices with performance, which generates inconsistent results in terms of generalizing the relationships between TQM and performance management.

\section{Conclusion}

It is apparent that the car brand quality and the level of service delivered to customer $s$ are principally two different concepts (Ahmad \& Butt, 2012). Nevertheless, the importance of after-sales as a main pillar of competitive advantage and business opportunity requires a transition from the conventional productorientation to customer-orientation, where the after-sales service plays the role as it is the main costumer voice. Furthermore, this transition necessitates the configuration of a comprehensive performance measurement system that enables the managers to measure and monitor the organisation's performance in an efficient manner (Gaiardelli et al., 2007).

This article encompasses two literature streams: TQM practices and KPIs in the automotive after-sales discipline, which provides a theoretical basis for the proposed model that links both antecedents. The authors have provided three main findings to advance research in addressing the effects of TQM practices on KPI in the service sector. To the best of the author's knowledge, no comprehensive model has emerged describing the relationships between multidimensional measurements of performance and total quality management, wherein the proposed hypothesis contends that the implementation of TQM practices at automotive dealerships to improvement of the synthesized financial and non-financial performance; therefore, the focus was firstly, to validate the measurability of TQM practices and prove empirically that the TQM practices are equivalently applicable across manufacturing and service sectors; secondly, to identify the synergetic set of KPIs and validate their robustness in representing the KPI 
formative construct; and thirdly, to determine whether the relationship between TQM and KPIs is statistically significant.

This study provides a practical approach to examine whether the implementation of TQM practices is feasible in the automotive after-sales context and affects their KPIs. Service managers should be aware of the high importance of all TQM practices with special focus on HR, information and analysis, and strategic planning practices under the TQM construct. In addition, the conceptual model implies explicitly the paramount importance of all TQM practices including soft and hard practices in advancing the performance figures in the automotive service centres. In particular, the model is considered a useful tool by which the service managers envisage the parametric performance in accordance to the TQM practices implemented in their departments, in other words, the model emphasise the practicality of all TQM practices in the automotive after sales discipline and its positive impact on the KPIs, wherein the selected KPIs demonstrate sufficient validity and reliability to be adopted by service managers in assessing the service department performance.

Despite the aforementioned findings, this study suffers from certain limitations that ought to be taken into consideration. Firstly, a longitudinal study would permit researchers to extract results that are more accurate on the level of TQM implementation and the precise values of KPIs. Secondly, despite the surveybased research being deemed as reliable and cost effective, there are still the risks of misconception by respondents and biasness in their answers, in addition to the geographical limitations and the particularity of the business domain

On the other hand, it is believed that the avenue of future research is to investigate the poor correlation in the three key dimension items of KPI formative construct: labour utilisation, labour gross profit and departmental profit in addition to enhancing the $\mathrm{R}^{2}$ of $\mathrm{KPI}$, which will be also necessary. The other direction of future research would be to insert a customer satisfaction as a mediator to test its influence on KPI.

We would like to express our deepest appreciation to the Ministry of Education (Malaysian International Scholarship MIS) for sponsoring the research under university grant GUP-2014-020.

\section{References}

Ahmad, S., \& Butt, M. M. (2012). Can after sale service generate brand equity? Marketing Intelligence \& Planning, 30(3), 307-323. https://doi.org/10.1108/02634501211226285.

Arokiasamy, A., \& Tat, H. H. (2014). Assessing the Relationship Between Service Quality and Customer Satisfaction in the Malaysian Automotive Insurance Industry. Middle-East Journal of Scientific Research, 20(9), 1023-1030. https://doi.org/10.5829/idosi. mejsr.2014.20.09.12029.

Barney, J. (2010). Gaining and sustaining competitive advantage (4th ed). Upper Saddle River: Prentice Hall.

Becker, J., Klein, K., \& Wetzels, M. (2012). Hierarchical Latent Variable Models in PLS-SEM: Guidelines for Using ReflectiveFormative Type Models. Long Range Planning, 45(5-6), 359-394. https://doi.org/10.1016/j. Irp.2012.10.001.

Bentes, A. V., Carneiro, J., da Silva, J. F., \& Kimura, H. (2012). Multidimensional assessment of organizational performance: Integrating BSC and AHP. Journal of Business Research, 65(12), 1790-1799. https://doi. org/10.1016/j.jbusres.2011.10.039.

Biondi, S., Calabrese, A., Capece, G., Costa, R., \& Di Pillo, F. (2013). A new approach for assessing dealership performance:Anapplication for the automotive industry. International Journal of Engineering Business Management, 5, 1-8. https://doi.org/10.5772/56662.

Bundschuh, R. G., \& Dezvane, T. M. (2003). How to make after-sales services pay off. McKinsey Quarterly, 4(4), 116-127.

Calvo-Mora, A., Navarro-Garcia, A., \& Perianez-Cristobal, R. (2015). Project to improve knowledge management and key business results through the EFQM excellence model. International Journal of Project Management, 33(8), 1638-1651. https://doi. org/10.1016/j.ijproman.2015.01.010.

Calvo-Mora, A., Ruiz-Moreno, C., PicónBerjoyo, A., \& Cauzo-Bottala, L. (2014). Mediation effect of TQM technical factors in excellence management systems. Journal of Business Research, 67(5), 769-774. https://doi. org/10.1016/j.jbusres.2013.11.042.

Cavalieri, S., Gaiardelli, P., \& lerace, S. (2007). Aligning strategic profiles with 
operational metrics in after-sales service. International Journal of Productivity and Performance Management, 56(5/6), 436-455. https://doi.org/10.1108/17410400710757132.

Chung Woon, K. (2000). TQM implementation: comparing Singapore's service and manufacturing leaders. Managing Service Quality: An International Journal, 10(5), 318-331. https://doi.org/https://doi. org/10.1108/09604520010345777.

Claver-Cortés, E., Pereira-Moliner, J., Tarí, J. J., \& Molina-Azorín, J. F. (2008). TQM, managerial factors and performance in the Spanish hotel industry. Industrial Management \& Data Systems, 108(2), 228-244. https://doi. org/10.1108/02635570810847590.

Corredor, P., \& Goñi, S. (2011). TQM and performance: Is the relationship so obvious? Journal of Business Research, 64(8), 830-838. https://doi.org/10.1016/j.jbusres.2010.10.002.

Development Finance and Enterprise Department of Bank Negara Malaysia. (2014). Circular on new definitionts of small and medium enterprises. Retrieved January 12, 2016, from http://www.bnm.gov.my/files/2013/ sme_cir_028_1_new.pdf.

FFM. (2008). Federation of Malaysian Manufacturers (FMM) Directory (2008). Malaysian industries (39th ed.). Kuala Lumpur, Malaysia: Federation of Malaysian Manufacturers.

Fotopoulos, C. B., \& Psomas, E. L. (2009). The impact of "soft" and "hard" TQM elements on quality management results. International Journal of Quality \& Reliability Management, 26(2), 150-163. https://doi. org/10.1108/02656710910928798.

Gaiardelli, P., Saccani, N., \& Songini, L. (2007). Performance measurement of the aftersales service network-Evidence from the automotive industry. Computers in Industry, 58(7), 698-708. https://doi.org/10.1016/j. compind.2007.05.008.

Hair, J., Black, W., Babin, B., \& Andersson, R. (2009). Multivariate Data Analysis (7th ed.). Upper Saddle River, NJ: Prentice Hall.

Hair, J., Hult, G. T. M., Ringle, C. M., \& Sarstedt, M. (2014). A Primer on Partial Least Squares Structural Equation Modeling (PLSSEM). USA: Sage publications, Inc.

Hung, R. Y. Y., Lien, B. Y. H., Yang, B., Wu, C. M., \& Kuo, Y. M. (2011). Impact of TQM and organizational learning on innovation performance in the high-tech industry.
International Business Review, 20(2), 213-225. https://doi.org/10.1016/j.ibusrev.2010.07.001.

Jabbour, C. J., Jabbour, A. B. L. de, Govindan, K., Teixeira, A. A., \& Freitas, W. R. de S. (2013). Environmental management and operational performance in automotive companies in Brazil: the role of human resource management and lean manufacturing. Journal of Cleaner Production, 47, 129-140. https://doi. org/10.1016/j.jclepro.2012.07.010.

Jayaram, J., Ahire, S. L., \& Dreyfus, P. (2010). Contingency relationships of firm size, TQM duration, unionization, and industry context on TQM implementation-A focus on total effects. Journal of Operations Management, 28(4), 345-356. https://doi. org/10.1016/j.jom.2009.11.009.

Kaynak, H. (2003). The relationship between total quality management practices and their effects on firm performance. Journal of Operations Management, 21(4), 405-435. https://doi.org/10.1016/S0272-6963(03)00004-4.

Kumar, R., Garg, D., \& Garg, T. K. (2011). TQM success factors in North Indian manufacturing and service industries. The TQM Journal, 23(1), 36-46. https://doi. org/10.1108/17542731111097470.

Kurdve, M., Zackrisson, M., Wiktorsson, M., \& Harlin, U. (2014). Lean and green integration into production system models experiences from Swedish industry. Journal of Cleaner Production, 85, 180-190. https://doi. org/10.1016/j.jclepro.2014.04.013.

Lam, S.-Y, Lee, V.-H, Ooi, K.-B., \& Phusavat, K. (2013). A structural equation model of TQM, market orientation and service quality: Evidence from a developing nation. Managing Service Quality: An International Journal, 22(3), 281-309. https://doi. org/10.1108/09604521211230996.

Large, R. O., \& Thomsen, C. G. (2011). Drivers of green supply management performance: Evidence from Germany. Journal of Purchasing and Supply Management, 17(3), 176-184. https://doi.org/https://doi. org/10.1016/j.pursup.2011.04.006.

Leong, T. K., Zakuan, N., \& Saman, M. Z. M. (2012). Quality Management Maintenance and Practices-Technical and Non-Technical Approaches. Procedia - Social and Behavioral Sciences, 65, 688-696. https://doi.org/10.1016/j. sbspro.2012.11.185.

Nair, A. (2006). Meta-analysis of the relationship between quality management 
practices and firm performance-implications for quality management theory development. Journal of Operations Management, 24(6), 948975. https://doi.org/10.1016/j.jom.2005.11.005.

Ooi, K.-B. (2014). TQM: A facilitator to enhance knowledge management? A structural analysis. Expert Systems with Applications, 41(11), 5167-5179. https://doi.org/10.1016/j. eswa.2014.03.013.

Pessôa, L. A. M., Lins, M. P. E., Da Silva, A. C. M., \& Fiszman, R. (2015). Integrating soft and hard operational research to improve surgical centre management at a university hospital. European Journal of Operational Research, 245(3), 851-861. https://doi.org/10.1016/j. ejor.2015.04.007.

Prajogo, D. I., \& Sohal, A. S. (2003). The relationship between TQM practices, quality performance, and innovation performance. International Journal of Quality \& Reliability Management, 20(8), 901-918. https://doi. org/10.1108/02656710310493625.

Rahman, S., \& Bullock, P. (2005). Soft TQM, hard TQM, and organisational performance relationships: an empirical investigation. Omega, 33(1), 73-83. https://doi.org/10.1016/j. omega.2004.03.008.

Sari, R. P. (2015). Integration of Key Performance Indicator into the Corporate Strategic Planning: Case Study at PT. Inti Luhur Fuja Abadi, Pasuruan, East Java, Indonesia. Agriculture and Agricultural Science Procedia, 3, 121-126. https://doi.org/10.1016/j. aaspro.2015.01.024.

Sawang, S. (2011). Key Performance Indicators for Innovation Implementation: Perception vs. Actual Usage. Asia Pacific Management Review, 16(1), 23-29. https://doi. org/10.6126/APMR.2011.16.1.02.

Smith, J. (2014). The KPIBook: The Ultimate Guide to Understanding the Key Performance Indicators of Your Business. Insight Training \& Development Limited.

Sofiyabadi, J., Kolahi, B., \& Valmohammadi, C. (2015). Key performance indicators measurement in service business: a fuzzy VIKOR approach. Total Quality Management \& Business Excellence, 27(9-10), 1024-1042. https://doi.org/ 10.1080/14783363.2015.1059272.
Suarez, E., Calvo-Mora, A., \& Roldán, J. L. (2016). The role of strategic planning in excellence management systems. European Journal of Operational Research, 248(2), 532542. https://doi.org/10.1016/j.ejor.2015.07.008.

Synodinos, N. E. (2003). The "art" of questionnaire construction: some important considerations for manufacturing studies. Integrated Manufacturing Systems, 14(3), 221-237. https://doi.org/https://doi. org/10.1108/09576060310463172.

Valmohammadi, C. (2011). The impact of TQM implementation on the organizational performance of Iranian manufacturing SMEs. The TQM Journal, 23(5), 496-509. https://doi. org/10.1108/175427311111157608.

Velimirović, D., Stanković, M. V., \& Rade. (2011). Role And Importance Of Key Performance Idicators Measurement. Serbian Journal of Management, 6(1), 63-72. https:// doi.org/doi:10.5937/sjm1101063V.

Omar Sabbagh

University Kebangsaan Faculty of Engineering \& Built Environment Department of Mechanical and Materials Engineering Malaysia omarsabbagh.omar@gmail.com

Mohd Nizam Ab Rahman

University Kebangsaan

Faculty of Engineering \& Built Environment Department of Mechanical and Materials Engineering Malaysia mnizam@ukm.edu.my

Wan Rosmanira Ismail University Kebangsaan Faculty of Science and Technology School of Mathematical Sciences Malaysia

Wan Mohd Hirwani Wan Hussain University Kebangsaan Graduate School of Business Malaysia 


\section{Abstract}

\section{THE IMPACT OF TQM PRACTICES ON KEY PERFORMANCE INDICATORS: EMPIRICAL EVIDENCE FROM AUTOMOTIVE DEALERSHIPS}

\section{Omar Sabbagh, Mohd Nizam Ab Rahman, Wan Rosmanira Ismail, Wan Mohd Hirwani Wan Hussain}

The automotive business is gradually transforming into a service-based business, while the aftersales (AS) service is becoming a strategic business driver to increase the capital revenue. The relationship between quality and performance management is still adversarial, wherein the nonfinancial aspect of performance measurements is significantly ignored. This research is conducted in the context of Malaysian automotive dealerships service centres in which the primary objectives are to identify the total quality management (TQM) practices and the financial and non-financial key performance indicators (KPIs) adopted in this sector, and to examine the impact of TQM practices on AS KPIs. Therefore, a conceptual model proposes that the high implementation of soft and hard dimensions of TQM has a positive impact on KPIs. A quantitative survey methodology was employed and a structured questionnaires was elaborated based on validated theoretical concepts, while the obtained data were analysed with the help of structural equation modelling (SEM) partial least squares technique (PLS). The results refer to equivalent applicability of TQM practices across manufacturing and service sectors, while the influence of TQM practices on the multi-oriented $\mathrm{KPIs}$ is empirically supported. The article contributes to the literature in service marketing and quality in which it streamlines two paradigms: TQM and performance management as it can form a guideline for scholars to deepen their relevant comprehension. In practice, the findings contribute to service managers by emphasising the importance of TQM practices for the improvement of service performance in both financial and non-financial aspects.

Key Words: Automotive, key performance indicators, total quality management, after-sales service, partial least square PLS.

JEL Classification: C3, L8.

DOI: 10.15240/tul/001/2019-1-008 